J.B.METZLER 
Tilmann Köppe/Simone Winko

\section{Neuere Literaturtheorien}

\section{Eine Einführung}

Verlag J. B. Metzler Stuttgart · Weimar 


\section{Autoren:}

Tilmann Köppe ist Junior Fellow an der School of Language and Literature des Freiburg Institute for Advanced Studies (FRIAS).

Simone Winko ist Professorin für Neuere deutsche Literatur (Schwerpunkt Literaturtheorie) an der Universität Göttingen.

Bibliografische Information der Deutschen Nationalbibliothek Die Deutsche Nationalbibliothek verzeichnet diese Publikation in der Deutschen Nationalbibliografie; detaillierte bibliografische Daten sind im Internet über $<$ http//dnb.d-nb.de $>$ abrufbar.

ISBN 978-3-476-02059-8

ISBN 978-3-476-05041-0 (eBook)

DOI 10.1007/978-3-476-05041-0

Dieses Werk einschließlich aller seiner Teile ist urheberrechtlich geschützt. Jede Verwertung außerhalb der engen Grenzen des Urheberrechtsgesetzes ist ohne Zustimmung des Verlages unzulässig und strafbar. Das gilt insbesondere für Vervielfältigungen, Übersetzungen, Mikroverfilmungen und die Einspeicherung und Verarbeitung in elektronischen Systemen.

(C) 2008 Springer-Verlag GmbH Deutschland

Ursprünglich erschienen bei J.B. Metzler'sche Verlagsbuchhandlung

und Carl Ernst Poeschel Verlag GmbH in Stuttgart 2008

www.metzlerverlag.de

info@metzlerverlag.de 


\section{Vorwort}

Dieses Buch ist der Versuch, Studierenden und Lehrenden auf dem unübersichtlichen Feld moderner Literaturtheorien eine klare Orientierung zu bieten. Es ist aus verschiedenen literaturtheoretischen Seminaren hervorgegangen und richtet sich nach den Bedürfnissen, die Teilnehmerinnen und Teilnehmer dieser Seminare formuliert haben: Es will einen strukturierten und umfassenden Überblick über aktuelle Literaturtheorien und Interpretationsmethoden geben, Kriterien formulieren, mit denen die Ansätze voneinander unterschieden werden können, und den Blick für die theoretischen Voraussetzungen von Interpretationen schärfen. Besonderen Wert legen wir in der Darstellung der unterschiedlichen Theorien auf Vergleichbarkeit.

Eine weniger ausführliche Version einiger Kapitel ist erschienen in: Thomas Anz (Hg.): Handbuch Literaturwissenschaft. Bd. 2: Theorien und Methoden. Stuttgart/ Weimar: Metzler 2007, 285-372. Für den vorliegenden Band wurden diese Kapitel überarbeitet, erweitert und um die Analyse exemplarischer Interpretationen ergänzt.

Bei den Mitarbeiterinnen und Mitarbeitern der Göttinger "Arbeitsstelle für Theorie der Literatur « bedanken wir uns für ihre Ideen in der Planungsphase dieses Bandes. Unser besonderer Dank gilt Fotis Jannidis, Tom Kindt, Jan Borkowski, Dorothee Birke und der Lektorin Ute Hechtfischer: Sie haben verschiedene Manuskriptversionen gelesen, auf ihre Praxistauglichkeit überprüft und, natürlich, kritisiert.

Göttingen und Freiburg, im August 2008 


\section{Inhalt}

Vorwort

1. Einleitung: Von der Unmöglichkeit, theoriefrei Literatur zu lesen, und der Notwendigkeit, sich literaturtheoretisch zu bilden

2. Was heißt > Literaturtheorie<?

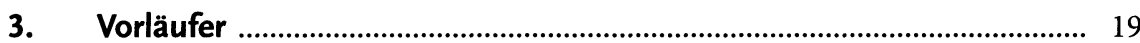

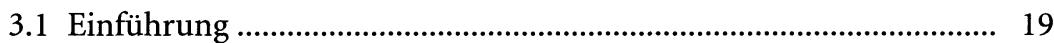

3.2 Hermeneutik............................................................................ 20

3.3 Formalismus und früher Strukturalismus ................................... 30

3.4 Werkimmanenz und New Criticism ................................................ 39

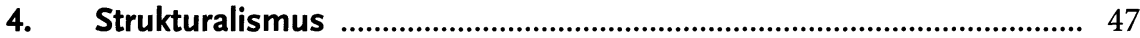

5. Psychoanalytische Literaturwissenschaft ........................................ 64

5.1 Das psychoanalytische Modell Sigmund Freuds .............................. 64

5.2 Die strukturale Psychoanalyse Jacques Lacans ................................. 76

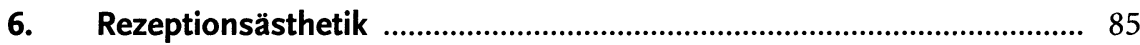

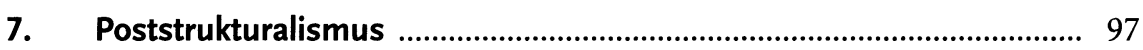

7.1 Was ist Poststrukturalismus? ...................................................... 97

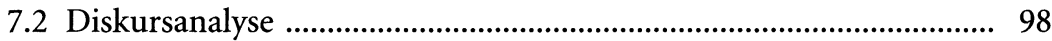

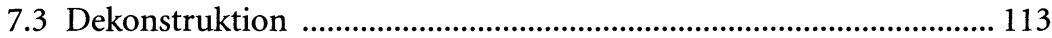

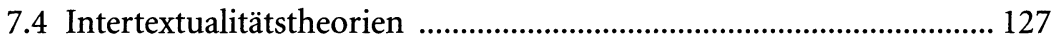

8. Hermeneutischer Intentionalismus (Neohermeneutik) ....................... 133

9. Gesellschaftswissenschaftliche Literaturtheorien ................................ 149

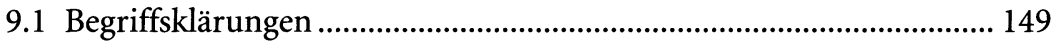

9.2 Marxismus und Ideologiekritik ...................................................... 150

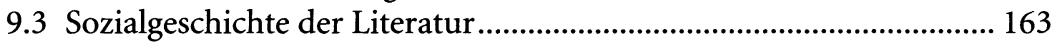

9.4 Systemtheorie der Literatur .............................................................. 175

9.5 Bourdieus Theorie des literarischen Feldes ...................................... 189 
10. Feministische Literaturwissenschaft und Gender Studies 201

11. Kulturwissenschaftliche Ansätze 217

11.1 Begriffsklärungen ......................................................................... 217

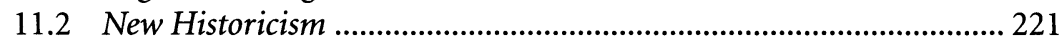

11.3 Kulturwissenschaftlich orientierte Literaturwissenschaft ............... 234

12. Medienwissenschaftliche Ansätze ......................................................... 255

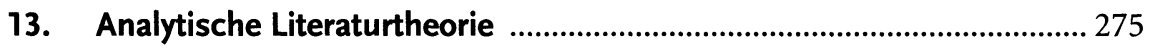

14. Empirische und kognitionswissenschaftliche Ansätze ......................... 293

14.1 Empirische Literaturwissenschaft ...................................................... 293

14.2 Cognitive Poetics ............................................................................... 300

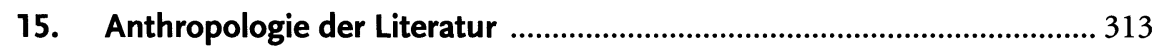

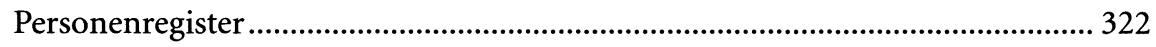

